\section{A new and simple extraction technique for rectal foreign bodies: removing by cutting into small pieces}

\author{
Abbas Aras, Mehmet Karabulut, Osman \\ Kones, Kaplan Baha Temizgonul, Halil Alis \\ Department of General Surgery, Bakirkoy \\ Dr. Sadi Konuk Training and Research \\ Hospital, Istanbul, Turkey
}

\begin{abstract}
The purposes of insertion and types of foreign bodies in rectum show great variation. Rectal foreign bodies need to be removed without giving damage to intestinal wall and this should be done in the easiest possible way. We have reported a new and a simple technique. It is easy to apply and safe. A patient was admitted to our clinic with a rectal foreign body (radish) which was successfully removed by cutting it into small pieces. We conclude that different kinds of rectal foreign bodies, especially fruit and vegetables, can be removed by this technique.
\end{abstract}

\section{Introduction}

Foreign bodies in the rectum are reported to be clinically rare. ${ }^{1}$ Various objects such as billy clubs, various fruit and vegetables, nails, light bulbs, and a turkey baster to a propane tank have been described as retained rectal foreign bodies. ${ }^{2}$ Objects can be thrust for diagnostic or therapeutic purposes or self-treatment of anorectal disease, forcefully and accidentally or most commonly for sexual purposes. ${ }^{3}$ Different tools and methods have been suggested for this purpose. ${ }^{1}$ Ideally, such objects are removed in the emergency department applying local anaesthesia and/or sedation, manual extraction and minimal instrumentation. Since minimal instrumentation is applicable in removing low lying rectal foreign bodies, simple manual extraction might not be successful in most cases. ${ }^{4}$ Even in experienced hands, the treatment of patients with retained colorectal foreign bodies is difficult. ${ }^{5}$ As a result, we reported a new and simple method to remove radish as a rectal foreign body which was inserted for hostility and punishment.

\section{Technical note}

A 53-year-old male came to the emergency department with a radish inserted into rectum the day before for punishment. At physical examination there was no rebound or tenderness in the abdomen. At rectal examination a big radish was noticed in rectum. Since it was too big, it was decided that it could not be extracted manually or with endoscopic manipulation. Plain abdominal X-rays were performed to rule out perforation (Figures 1 and 2). Since the foreign body was a vegetable, removal by cutting into small pieces was planned. We decided to remove the foreign body by cutting it into small pieces with the surgical tools at operating room with a new and simple technique. At the operation room, under general anaesthesia in the lithotomy position, an anoscope was inserted into anal canal and fixed to perianal skin not to give damage to sphincters (Figure 3). Periosteal elevators were inserted between foreign body and intestinal wall not to give damage. Ronger, bone clamp and periosteal elevators were used for cutting (Figures 4 and 5). A corkscrew was inserted into the radish for traction and counter traction movements for easy manipulation. After removing the foreign body, colonoscopic examination revealed that mucosa of rectum and sigmoid were normal. The patient was discharged the following day.

\section{Discussion}

Most of the swallowed bodies are excreted (80-90\%), others require endoscopic removal (10-20\%), but very few (1\%) require surgical intervention. ${ }^{6}$ Foreign bodies placed in rectum could be low or high lying. Generally, while lowlying rectal foreign objects can be easily removed, the high lying ones are difficult to remove. ${ }^{7}$ In removing foreign body in rectum the main purpose is to apply the minimally invasive method without giving damage to intestinal wall. As to removing difficult objects without colonic perforation, they should be removed by transanal route under deep anaesthesia. Laparoscopy should be considered in cases with perforation, ischemia as well as large objects. ${ }^{8}$ Many instruments and methods have been suggested to remove foreign objects. When the foreign body is inserted into rectum for hostility and punishment, generally big and hard objects are chosen to give physical pain. In our case a big radish was detected which could not be extracted manually or manipulated by endoscopy. The main goal in removing rectal foreign bodies is to remove the foreign bodies without giving damage to intestinal wall by using the simplest method and minimal tools. In our case there was a low-lying located foreign body which was too big to extract with manual extraction. We could not find a method in literature to remove a low lying located foreign body in such a size. The radish was too big to remove
Correspondence: Abbas Aras, Department of General Surgery, Bakirkoy Dr. Sadi Konuk Training and Research Hospital, Zuhuratbaba Mh, 34307 Istanbul, Turkey.

Tel: +90.212.6962311 - Fax:+90.212.5424491.

E-mail: abbasaras76@mynet.com

Key words: foreign body, rectum, rectal and anal surgery.

Received for publication: 6 July 2014

Revision received: 16 December 2014

Accepted for publication: 16 December 2014

This work is licensed under a Creative Commons Attribution NonCommercial 3.0 License (CC BYNC 3.0).

(C) Copyright A. Aras et al., 2014

Licensee PAGEPress, Italy

Surgical Techniques Development 2014; 4:5538

doi:10.4081/std.2014.5538

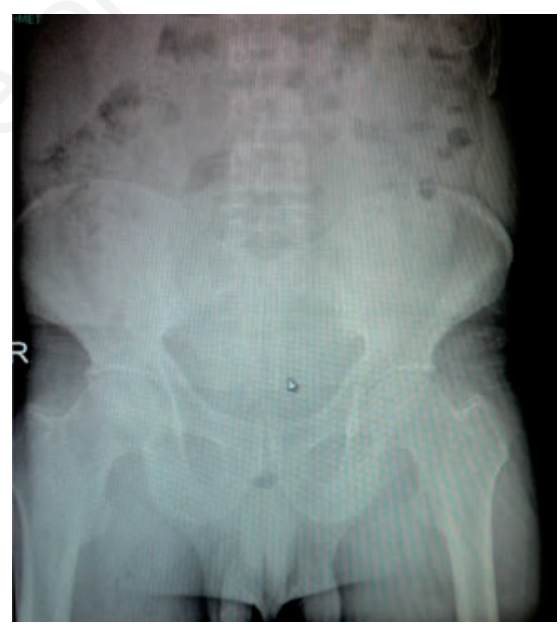

Figure 1. X-rays performed to rule out perforation.

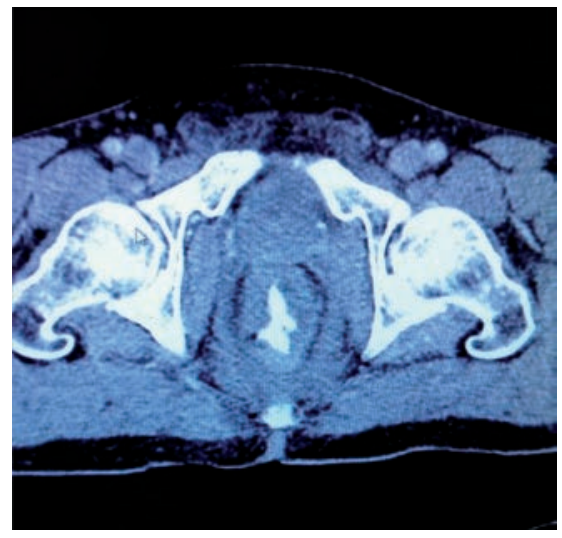

Figure 2. Scan of the rectum. 


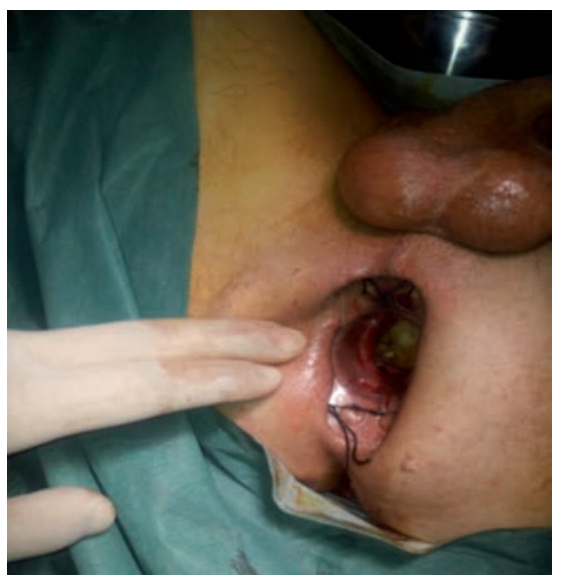

Figure 3. Anoscope inserted into anal canal and fixed to perianal skin.

and there was risk of sphincter damage and intestinal injury. So we did not remove just with corkscrew. Since the radish was low lying located and easy to cut, we decided to remove it cutting into small pieces. Despite the above mentioned precautions, injuries on intestinal walls may occur. We believe that the attention the surgeon shows will minimise this risk. Clark and others used corkscrew to remove a dildo. ${ }^{9}$ Kasotakis and colleagues reported a case with pubic symphysiotomy due to extraction of foreign body. ${ }^{10}$ Glaser and colleagues used argon plasma coagulation to remove an apple in rectum. ${ }^{11}$

\section{Conclusions}

In our case the radish was so adjacent to rectal wall that we did not use argon plasma coagulation not to give damage. In removing foreign bodies by cutting into small pieces, tools can easily be found in every operating room and the technique is easy to understand and to apply.

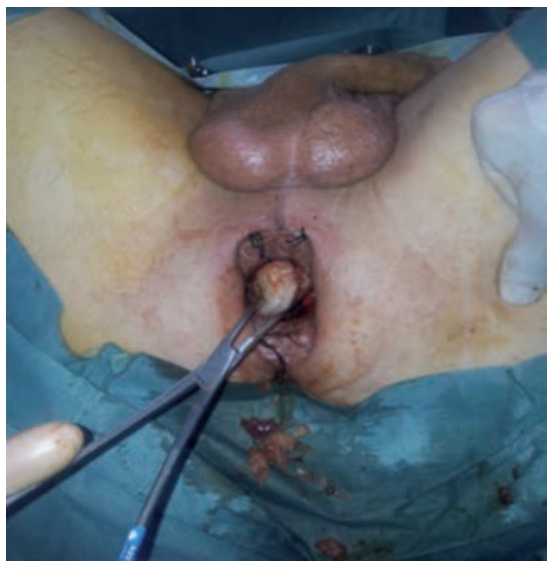

Figure 4. Ronger used during the operation.

Single port laparoscopic technique by transanal route has been reported as a new approach to remove rectal foreign objects. ${ }^{4,7}$ We concluded that removal by cutting into small pieces can only be used in removing such low lying rectal organic foreign bodies, which can be easily cut and cannot be removed with manual extraction because of their big size.

\section{References}

1. Caliskan C, Karaca C, Akgun E, Korkut MA. A new extraction technique for rectal foreign bodies with a rubber band ligation device. Surg Today 2010;40:583-5.

2. Goldberg JE, Steele SR. Rectal foreign bodies. Surg Clin N Am 2010;90:173-84.

3. Koornstra JJ, Weersma RK. Management of rectal foreign bodies: description of a new technique and clinical practice guidelines. World J Gastroentero 2008;14:4403-6.

4. Bak Y, Merriam M, Neff M, Berg DA. Novel approach to rectal foreign body extraction.

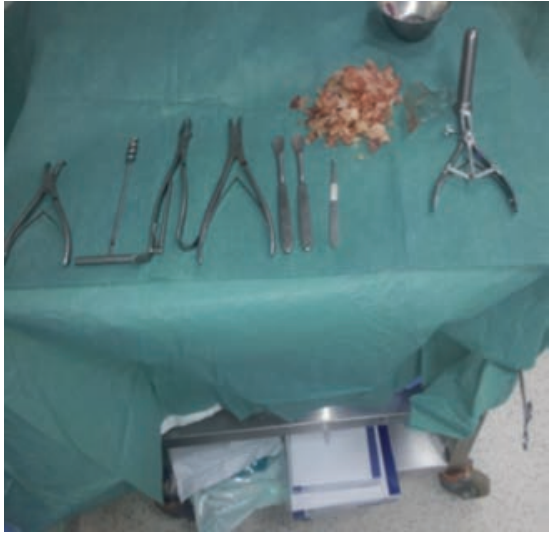

Figure 5. Cutting instruments used to extract the radish.

JSLS-J Soc Laparoend 2013;17:342-5.

5. Lake JP, Essani R, Petrone P, et al. Management of retained colorectal foreign bodies: predictors of operative intervention. Dis Colon Rectum 2004;47:1694-8.

6. Anderson KL, Dean AJ. Foreign bodies in the gastrointestinal tract andanorectal emergencies. Emerg Med Clin N Am 2011;29:369-400.

7. Elias B, Debs T, Hage T, et al. Single incision laparoscopic surgery technique for transanal removal of rectal foreign body. $\mathrm{J}$ Surg Case Rep 2014;2014:3.

8. Coskun A, Erkan N, Yakan S, et al. Management of rectal foreign bodies. World J Emerg Surg 2013;8:11.

9. Clark SK, Karanjia ND. A cork in a bottle. A simple technique for removal of a rectal foreign body. Ann Roy Coll Surg 2003;85:282.

10. Kasotakis G, Roediger L, Mittal S. Rectal foreign bodies: a case report and review of the literature. Int J Surg Case Rep 2012;3:111-5.

11. Glaser J, Hack T, Rübsam M. Unusual rectal foreign body: treatment using argon-beam coagulation. Endoscopy 1997;29:230-1. 